\title{
Peri-operative management of ophthalmic patients on anti-thrombotic agents: a literature review
}

\author{
A. K. Makuloluwa' ${ }^{1}$ S. Tiew $\mathbb{D}^{1} \cdot$ M. Briggs ${ }^{1}$
}

Received: 19 August 2018 / Revised: 25 December 2018 / Accepted: 20 January 2019 / Published online: 8 March 2019

(c) The Royal College of Ophthalmologists 2019

\begin{abstract}
There is variability in the management of ophthalmic patients on anti-thrombotic agents (antiplatelets and anticoagulants) during the peri-operative period. A survey carried out in a UK teaching hospital on a cohort of ophthalmologists showed majority were comfortable with antiplatelet management but there was variability in managing patients on warfarin and direct oral anticoagulants (DOACs); $40 \%$ were unaware of existing guidelines. We aim to review the recommendations in the literature with regards to managing anti-thrombotic agents during the peri-operative period of ophthalmic surgery. We reviewed incidences of complications, specifically, the haemorrhagic complications associated. Pubmed search was carried out on relevant keywords from January 2007 to August 2017. All relevant UK guidelines including the Royal College of Ophthalmologists and British Society of Haematology were reviewed. Literature recommendations for routine cataract surgery under topical or sub-Tenon's anaesthesia would be to continue all anti-thrombotic agents. For sharp needle anaesthesia, avoidance of dual antiplatelet therapy was recommended and warfarin could be continued if INR within therapeutic range. Recommendations for surgeries in glaucoma, vitreo-retinal, oculoplastic and lacrimal; and strabismus are presented. No evidence was found for corneal surgery. Haemorrhagic complications are reported in all groups. Limitations of this review include the retrospective nature, lack of randomized control trials and the limited evidence regarding DOACs. It is important for ophthalmologists to be aware of and balance the risk of thromboembolic events and risks of haemorrhagic complications for ophthalmic surgery. A multi-disciplinary approach is recommended for complex cases.
\end{abstract}

\section{Introduction}

Anti-thrombotic agents, used in the prevention and treatment of cardiovascular and ischaemic cerebral diseases, are classified into antiplatelet and anticoagulant agents. With an ageing population, there is an increasing prevalence of ophthalmic patients on anti-thrombotic agents. Oh et al. reported 14.6, 28.5 and 32.3 of patients undergoing vitreoretinal surgery were on antiplatelet agents in 1993, 2004 and 2008, respectively [1]. In this study, warfarin use

This work has previously been presented at the Royal College of Ophthalmology Congress May 2018 (Liverpool) as a poster presentation.

A. K. Makuloluwa

aruni_ar@hotmail.com

1 St. Paul's Eye Unit, Royal Liverpool University Hospital, Liverpool L7 8XP, UK (an anticoagulant) was reported in $0.9 \%, 3.9 \%$ and $3.6 \%$ of patients in 1993, 2004 and 2008, respectively [1].

Continuing anti-thrombotic agents peri-operatively may increase the risk of potentially sight-threatening haemorrhagic complications, whereas discontinuing these medications may increase the risk of life-threatening thromboembolic events. Therefore, it is important to understand the indications of antithrombotic agents and when it may be safe to discontinue them peri-operatively. Similarly, it is essential to stratify ophthalmic surgeries depending on the risk of peri-operative haemorrhagic complications. The British Society of Haematology (BSH) recommends that the surgeon assesses the risk of haemorrhagic complications for individual patients, discuss these risks with the patient and record the peri-operative and discharge plan in patient's notes [2]. It is vital that a multidisciplinary approach is taken when complex situations arise to ensure that the safest option is chosen for each patient depending on their individual thromboembolic and haemorrhagic risk factors.

The first aim of this review is to discuss the different types of antiplatelet and anticoagulant agents, their 
indications and when patients should be considered for bridging anticoagulation. Our second aim is to discuss the reported incidences of haemorrhagic complications associated with the different types of ophthalmic surgeries and to review the recommendations made in the literature.

\section{Methods}

We reviewed the guidelines produced by the BSH, Royal College of Ophthalmologists (RCOphth) and our local Trust on peri-operative management of patients on antithrombotic agents. We also undertook a literature review using relevant keywords on articles published in English from January 2007 to August 2017.

\section{Antiplatelet Agents}

Various antiplatelet agents are prescribed for various indications, predominantly for the treatment and primary and secondary prevention of cardiovascular and ischaemic cerebral diseases (Fig. 1). Aspirin is a cyclooxygenase-1 (COX1) inhibitor, which in turn inhibit thromboxane A2 formation and therefore platelet aggregation [3, 4]. Clopidogrel, prasugrel and ticagrelor inhibit $\mathrm{P}_{2} \mathrm{Y}_{12}$ receptors (ADP receptors) found in platelets that are involved in platelet aggregation [5]. Clopidogrel and prasugrel irreversibly inhibit this receptor, whereas ticagrelor reversibly inhibits the same receptor on platelets $[4,6]$. Dual antiplatelet therapy (DAPT), a combination of aspirin and a $\mathrm{P} 2 \mathrm{Y}_{12}$ receptor inhibitor, is indicated following acute coronary syndromes and coronary artery stenting [2]. Dipyridamole is another antiplatelet agent that inhibits platelet aggregation by inhibiting phosphodiesterase thereby increasing cAMP (cyclic adenosine monophosphate) levels in platelets [7].

The BSH guidelines recommend continuing aspirin indicated for secondary prevention of cardiovascular diseases if patients are undergoing low haemorrhagic risk procedures and discontinuing if undergoing high haemorrhagic risk procedures [2]. A randomized, double-blind, placebo-controlled study has shown that discontinuing aspirin for 7 days pre-operatively and re-starting 3 days post-operatively resulted in a significant increase to Major Adverse Cardiac Events (MACE) $(9.0 \%$ vs. $1.8 \%, p=0.02)$ and no significant difference to the peri-operative blood loss

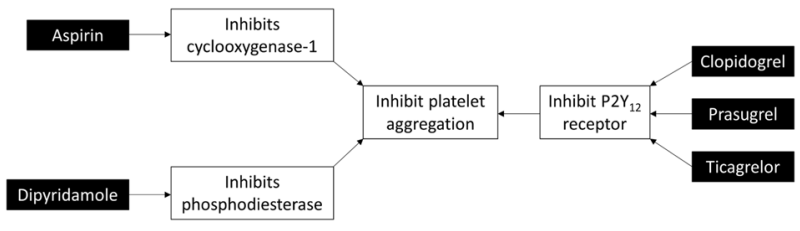

Fig. 1 Mechanisms of action of antiplatelet agents in patients with stable cardiovascular disease undergoing high-risk elective surgery compared to those that continued aspirin peri-operatively [2]. The increased risk of MACE in patients who discontinued antiplatelet agents has been suggested to be due to a rebound platelet re-activity as well as due to the pro-inflammatory and pro-thrombotic effects of surgery itself [8]. There is limited evidence on clopidogrel and it has been suggested to follow the same guidelines as aspirin in patients on clopidogrel [2].

In contrast to aspirin monotherapy, DAPT has been associated with an increased risk of haemorrhagic complications during surgery (14.7\% vs. 4.1\%) [2]. Patients undergoing coronary artery bypass graft surgery were found to have similar incidences of haemorrhagic events with aspirin and ticagrelor dual therapy, but increased risk with aspirin and prasugrel dual therapy, when compared to patients on aspirin and clopidogrel dual therapy [2]. DAPT is indicated for patients following acute coronary syndromes and coronary artery stenting for at least 4 weeks following bare metal stent insertion and for 12 months following drug-eluting stent insertion [2]. The risk of MACE is greatest within the first month after stent insertion and gradually reduces over the first one year [2]. Early discontinuation of DAPT following stent insertion has been associated with ischaemic complications: discontinuing clopidogrel within 30 days has been shown to increase the risk of death by ten-folds in the following 11 months compared to those who continued the medication [9]. Therefore, BSH guidelines recommend that DAPT is continued in patients undergoing "very low bleeding risk" procedures, whereas the $\mathrm{P}_{2} \mathrm{Y}_{12}$ receptor inhibitor may be discontinued temporarily with continuation of aspirin in patients undergoing "low bleeding risk" procedures who have a low thromboembolic risk [2]. If patients are at risk of high thromboembolic risk, elective surgery should be postponed until the patient is deemed to have a low risk of thromboembolism, that is a minimum of 4 to 6 weeks (preferably 3 months) after bare metal stent insertion and 6 months (preferably 12 months) after drug-eluting stent insertion [2]. After this high-risk period, aspirin should be continued in these patients, whereas the $\mathrm{P}_{2} \mathrm{Y}_{12}$ receptor inhibitors may be discontinued temporarily [2]. If patient requires urgent surgery, aspirin is to be continued with temporary discontinuation of the $\mathrm{P}_{2} \mathrm{Y}_{12}$ receptor inhibitor (clopidogrel/ticagrelor for 5 days and prasugrel for 7 days pre-operatively) [2]. This is recommended for patients undergoing urgent intracranial, spinal canal and posterior eye chamber surgery who are within the high thromboembolic risk period [2]. In patients with high thromboembolic risks requiring high bleeding risk surgery that is urgent, bridging with a parenteral short-acting glycoprotein IIb/IIIa inhibitor (tirofiban or eptifibatide) should be considered while $\mathrm{P}_{2} \mathrm{Y}_{12}$ receptor inhibitors are discontinued [2]. 


\section{Anticoagulant Agents}

\section{Warfarin}

Warfarin inhibits vitamin K-dependent gamma-carboxylation of coagulation factors II, VII, IX and X (Fig. 2) [10]. It also inhibits the formation of proteins $\mathrm{C}$ and $\mathrm{S}$ of the coagulation pathway [10]. Warfarin has an approximate half-life of thirtysix hours and therefore needs to be discontinued 5 days preoperatively to ensure normal haemostasis and international normalized ratio (INR) needs to be checked on the day of surgery [2]. Due to slow onset of action, warfarin may be restarted on the evening of surgery or the next day if adequate haemostasis has been achieved [2].

\section{Direct Oral Anticoagulants (DOACs)}

DOACs (dabigatran, rivaroxaban, apixaban, edoxaban) are indicated for stroke prevention in non-valvular atrial fibrillation (AF) and treatment and prevention of deep venous thrombosis (DVT) and pulmonary embolism (PE) [2]. They are given as a fixed once or twice daily dose regimens and do not require regular laboratory monitoring [6]. Unlike warfarin, they have fewer food and drug interactions [6]. However, renal function needs to be monitored as most are excreted via the kidneys, especially dabigatran $(80 \%$ excreted via kidneys) $[6,9]$. Major limitations of DOACs are that they lack a reversing agent in the event of a haemorrhagic complication and currently there are no standard tests to measure the anticoagulant effect [6]. Idarucizumab is an approved reversal agent for dabigatran and andexanet, when available, can be used to reverse apixaban, rivaroxaban or edoxaban [2].

The RE-LY study included 4951 patients whose dabigatran was temporarily discontinued for 1 to 5 days prior to various surgical and invasive procedures, depending on the renal function $[2,11]$. Of the study population, 9.3\% underwent cataract surgery and all patients were monitored for up to 30 days post operatively. The authors reported that there was no statistically significant difference in the incidence of major haemorrhages between the dabigatran group and warfarin group (discontinued 5 days pre-operatively).

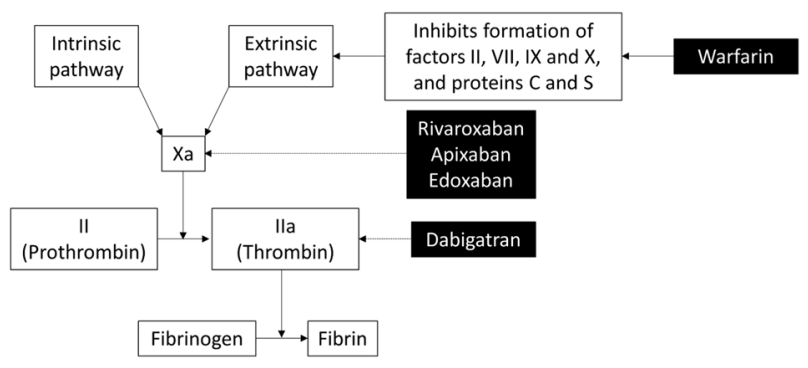

Fig. 2 Mechanisms of action of anticoagulant agents
The incidences of stroke and systemic embolism were $0.5 \%$ in each group during the first 30 days of discontinuation [2, 11]. Another multicentre prospective study that included 324 standard risk and 217 high haemorrhagic risk procedures reported an incidence rate of $1.8 \%$ for major bleeding (0.7-3.0\%) and $0.2 \%(0-0.5 \%)$ for thromboembolic events in the first 30 days of discontinuation of dabigatran preoperatively [2].

The Rocket-AF study reported no significant difference in the incidences of haemorrhagic or thromboembolic events in patients who underwent 2980 procedures $(8 \%$ ophthalmic procedures) when rivaroxaban was discontinued for three or more days compared to when warfarin was discontinued [2]. The Aristotle study investigated 9260 procedures (8\% ophthalmic procedures) of which $60 \%$ were undertaken in patients who discontinued apixaban [2]. Most of the procedures were deemed low risk of haemorrhage. There were no significant differences to the incidence of haemorrhagic complications in patients taking apixaban compared to warfarin irrespective of whether or not anticoagulation was discontinued [2].

Sun et al. reported findings of a systematic review and meta-analysis of twelve phase 3 randomised controlled trials (RCTs) published until August 2016 on events of intraocular haemorrhage in patients on DOACs [12]. This study included 102627 patients on DOACs (4 studies on rivaroxaban, 4 on dabigatran, 2 on apixaban and 2 on edoxaban) compared to warfarin that were indicated for $\mathrm{AF}$ or venous thromboembolism (VTE). Their findings showed that there is a $22 \%$ relative reduction in intraocular haemorrhagic events in patients on DOACs compared to those on warfarin (risk ratio $0.78,95 \%$ CI $0.61-0.99$ ). This was irrespective of the indication for DOAC and type of DOAC used by the patient [12]. The BSH guidelines for perioperative management of DOACs are shown in Table 1.

\section{Bridging Anticoagulants}

There is evidence that temporary discontinuation of anticoagulant agents lead to a transient hypercoaguable state with a rapid increase in clotting factors, thus increasing the risk of thromboembolic events [13]. Bridging anticoagulation is the introduction of a therapeutic dose short-acting anticoagulant agent during temporary interruption of oral anticoagulants described above [9]. These short-acting anticoagulants are sub-cutaneous low molecular weight heparin (LMWH) and intravenous unfractionated heparin (UFH) [9]. They inhibit thrombin (factor IIa) and Xa, however, LWMH predominantly inhibit factor Xa than IIa [14]. Due to the shorter half-lives of DOACs, it has been suggested that bridging anticoagulation is not required peri-operatively when DOACs are temporarily discontinued [6, 9]. If bridging anticoagulation is given peri-operatively, it is important to 
Table 1 BSH guidelines on peri-operative management of direct oral anticoagulant agents

\begin{tabular}{llll}
\hline \multirow{2}{*}{ DOAC } & & \multicolumn{2}{l}{ Risk of haemorrhage associated with surgery } \\
\cline { 3 - 4 } Dabigatran & Renal function CrCL $(\mathrm{mL} / \mathrm{min})$ & Low & High \\
& $\geq 80$ & Stop $24 \mathrm{~h}$ pre-operatively & Stop $48 \mathrm{~h}$ pre-operatively \\
& $\geq 50$ and $<80$ & $24-48 \mathrm{~h}$ pre-operatively & $48-72 \mathrm{~h}$ pre-operatively \\
Rivaroxaban Apixaban Edoxaban & $\geq 30$ to $<50$ & $48-72 \mathrm{~h}$ pre-operatively & $72-96 \mathrm{~h}$ pre-operatively \\
& $\geq 30$ & $24 \mathrm{~h}$ pre-operatively & $48 \mathrm{~h}$ pre-operatively \\
& $<30$ & $48 \mathrm{~h}$ pre-operatively & $72 \mathrm{~h}$ pre-operatively \\
\hline
\end{tabular}

Re-start DOACs 6-12 h and $48 \mathrm{~h}$ after low and high-risk procedures, respectively, if adequate haemostasis if achieved

If patient is at high risk of thromboembolic events, prophylactic anticoagulation may be considered prior to re-starting full therapeutic dose of DOAC

CrCL Creatinine clearance $(\mathrm{mL} / \mathrm{min})$

note that DOACs and bridging anticoagulation must not be given simultaneously [8]. This is in contrast to warfarin, when bridging anticoagulation is given post-operatively until INR is within therapeutic level after re-starting warfarin. Although the evidence from RCTs are limited, there are evidence from systematic reviews and meta-analyses that show that bridging anticoagulation is associated with an increased risk of haemorrhage and with uncertain absolute reduction of thromboembolic events [2,9].

Guidelines on the use of bridging anticoagulation as recommended by BSH and our local Trust guidelines are shown in Fig. 3. The requirement for bridging anticoagulation in the presence of mechanical heart valves (MHV) depend on the location of the valve, type of valve and co-existence of stroke risk factors [2]. For patients with $\mathrm{AF}$ the $\mathrm{CHADS}_{2}$ score (congestive cardiac failure, hypertension, age $\geq 75$, diabetes mellitus and previous stroke or transient ischaemic attack (TIA)) can be used to predict the risk of stroke and select patients who may require bridging anticoagulation [2]. For patients with acute VTE the risk of recurrence without anticoagulation is more than $10 \%$ per year in the first 3 months and surgery will increase this risk further [9]. Beyond this high-risk period, the anticoagulation is for secondary prevention when prophylactic dose of LMWH can be given instead of treatment dose until the INR is within therapeutic range [9]. Bridging therapy should also be considered for patients who have had previous VTE while on therapeutic anticoagulation who now have a target INR of 3.5, active metastatic cancers and patients with thrombophilia [2,9].

The last dose of therapeutic LMWH should be given at least 24 hours pre-operatively and some recommend giving half the therapeutic dose. Post-operatively, bridging anticoagulation should not be started at least after 48 hours of high-risk surgery and only when adequate haemostasis has been achieved [2,9]. However, prophylactic doses may be given within the first 48 hours if indicated [2]. Bridging anticoagulation is to be continued until INR is within therapeutic range after re-starting warfarin post-operatively [9].

\section{Haemorrhagic Complications Associated With Ophthalmic Surgeries - Risk Stratification}

\section{Ophthalmic Anaesthesia}

Cataract surgery is the most (Table 2) commonly performed ophthalmic surgery in the UK [15]. The number of surgeries has quadrupled from approximately 100000 per year in 1990 to over 400000 per year in England between 2016 and 2017 [15-17]. Almost 97\% of these operations are performed under local anaesthesia [18]. A recent British Ophthalmological Surveillance Unit (BOSU) study showed that the current usage of local anaesthesia are $39 \%$ for topical (with or without intracameral), 51\% for sub-Tenon's, $9 \%$ for peribulbar, and $1 \%$ for retrobulbar anaesthesia [18]. The latest NICE guidelines recommend offering patients sub-Tenon's, or topical (with or without intracameral) anaesthesia for patient undergoing cataract surgery [17]. If these are contraindicated, offer peri-bulbar anaesthesia. However, they do not recommend retro-bulbar anaesthesia for patients undergoing cataract surgery.

The literature to date reports no sight-threatening complications associated with local anaesthetic blocks in patients who are on single antiplatelet agents or on anticoagulant agents. Most complications reported are subconjunctival haemorrhages that resolve spontaneously without affecting vision. Benzimra et al. reported an increased risk of self-limiting sub-conjunctival haemorrhages with clopidogrel $(4.4 \%)$ and warfarin $(3.7 \%)$ compared to non-anti-thrombotic users $(1.7 \%)$ who had subTenon's or sharp needle anaesthesia [19]. However, the authors did not clarify if these anti-thrombotic agents were continued or discontinued peri-operatively. Kobayashi et al. reported the incidence sub-conjunctival haemorrhages to be 
Fig. 3 Indications for bridging anticoagulation (BSH and local Trust guidelines, Kong 2015)

\begin{tabular}{|c|c|c|c|}
\hline \multicolumn{4}{|c|}{$\begin{array}{l}\text { (1) MECHANICAL HEART VALVES } \\
\text { *NOTE: if type of valve cannot be verified start bridging anticoagulation }\end{array}$} \\
\hline High risk & & 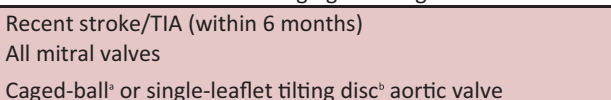 & $\begin{array}{l}\text { Bridging strongly } \\
\text { recommended }\end{array}$ \\
\hline $\begin{array}{l}\text { Moderate } \\
\text { risk }\end{array}$ & & $\begin{array}{l}\text { Bileaflet tilting disc aortic valve and one or more stroke risk } \\
\text { factors }^{\star}\end{array}$ & $\begin{array}{l}\text { Bridging should be } \\
\text { considered }\end{array}$ \\
\hline Low risk & & $\begin{array}{l}\text { Bileaflet tilting disc aortic valve without AF and no other risk } \\
\text { factors for stroke }\end{array}$ & Bridging optional \\
\hline \multicolumn{4}{|c|}{$\begin{array}{l}\text { 'Starr-Edwards } \\
\text { 'Bjork-Shiley, Medtronic-Hall or Omnicarbon valve } \\
\text { 'St Jude or Carbomedics valve } \\
\text { 'Stroke risk factors: AF, previous stroke/TIA, congestive heart failure/reduced left ventricular ejection fraction, } \\
\text { age }>75 \text { years, hypertension, diabetes mellitus }\end{array}$} \\
\hline \multicolumn{4}{|c|}{ (2) ATRIAL FIBRILLATION } \\
\hline High risk & & $\begin{array}{l}\text { Recent stroke/TIA (within } 3 \text { months) } \\
\text { Rheumatic heart disease } \\
\mathrm{CHADS}_{2} 5 \text { or } 6^{\circ}\end{array}$ & $\begin{array}{l}\text { Bridging strongly } \\
\text { recommended }\end{array}$ \\
\hline $\begin{array}{l}\text { Moderate } \\
\text { risk }\end{array}$ & & $\mathrm{CHADS}_{2} 3$ or $4^{\circ}$ & $\begin{array}{l}\text { Bridging should be } \\
\text { considered }\end{array}$ \\
\hline Low risk & & $\mathrm{CHADS}_{2}$ score $0-2^{\circ}$ (and no prior stroke/TIA) & $\begin{array}{l}\text { Bridging rarely } \\
\text { necessary }\end{array}$ \\
\hline \multicolumn{4}{|c|}{$\begin{array}{l}{ }^{\circ} \mathrm{CHADS}_{2} \text { score: Congestive heart failure/LV dysfunction (1), Hypertension (1), Age > } 75 \text { years (1), Diabetes } \\
\text { Mellitus (1), previous Stroke/TIA (2) }\end{array}$} \\
\hline \multicolumn{4}{|c|}{ (3) VENOUS THROMBOEMBOLISM } \\
\hline High risk & & $\begin{array}{l}\text { Recent (within } 3 \text { months) of VTE } \\
\text { Severe thrombophiliaa }\end{array}$ & $\begin{array}{l}\text { Bridging strongly } \\
\text { recommended }\end{array}$ \\
\hline $\begin{array}{l}\text { Moderate } \\
\text { risk }\end{array}$ & & $\begin{array}{l}\text { VTE within past } 3 \text { to } 12 \text { months } \\
\text { Non-severe thrombophilic conditions } \\
\text { Recurrent VTE } \\
\text { Active cancer (Rx within } 6 \text { months or palliative) }\end{array}$ & $\begin{array}{l}\text { Bridging should be } \\
\text { considered }\end{array}$ \\
\hline Low risk & & Single VTE more than 12 months and no other risk factors & $\begin{array}{l}\text { Bridging rarely } \\
\text { necessary }\end{array}$ \\
\hline \multicolumn{4}{|c|}{$\begin{array}{l}\text { 'Deficiency of protein } \mathrm{C} \text { or } \mathrm{S} \text { or anti-thrombin, antiphospholipid antibodies, multiple abnormalities } \\
\text { ' Heterogenous factor } \mathrm{V} \text { Leiden mutation, prothrombin gene mutation } \\
\text { - For some individual patients the use of vena cava filter may need to be discussed. }\end{array}$} \\
\hline \multicolumn{4}{|c|}{$\begin{array}{l}\text { High risk: }>10 \% \text { per year risk of arterial thromboembolism or }>10 \% \text { per month risk of venous } \\
\text { thromboembolism } \\
\text { Moderate risk: } 4-10 \% \text { per year risk of arterial thromboembolism or } 4-10 \% \text { per month risk of venous } \\
\text { thromboembolism }\end{array}$} \\
\hline
\end{tabular}

$17.2 \%$ in patients on continued aspirin, warfarin or both prior to sub-Tenon's anaesthesia, which was statistically significant compared to patients whose anti-thrombotic agents were discontinued for 1 week pre-operatively [20]. This is in contrast to patients on DAPT, who may have an increased risk of sight-threatening haemorrhagic complications. It is recommended either that elective ophthalmic procedures are postponed until it is safe for the patient to discontinue one of the antiplatelet agents during the perioperative period or perform the surgery under less invasive anaesthetic routes, for example, under topical anaesthesia.

\section{Cataract Surgery}

Antiplatelet agents (Table 3), when used either as monotherapy or dual therapy, have not been associated with an increased risk of haemorrhagic complications. However, if surgery is carried out under peri- or retro-bulbar anaesthetic block, it is recommended that the $\mathrm{P}_{2} \mathrm{Y}_{12}$ receptor inhibitors are discontinued peri-operatively after the high-risk thromboembolic period [21]. This is due to haemorrhagic risks associated with the anaesthetic block rather than the cataract surgery itself.

Jamula et al. undertook a systematic review of the literature to study the incidence of haemorrhagic complications in patients continuing warfarin peri-operatively during cataract surgery [22]. They analysed 11 studies (4 cohort, 1 RCT and 6 case series) and reported increased risk of bleeding in patients taking warfarin $(10 \%)$ with an odds ratio of 3.26 compared to non-anticoagulated patients undergoing surgery. However, most were self-limiting and non-significant events that included dot hyphaema and subconjunctival haemorrhages. They concluded that there was no evidence that continuation of warfarin was associated with sight-threatening haemorrhagic complications during cataract surgery [22]. The RCOphth recommends 


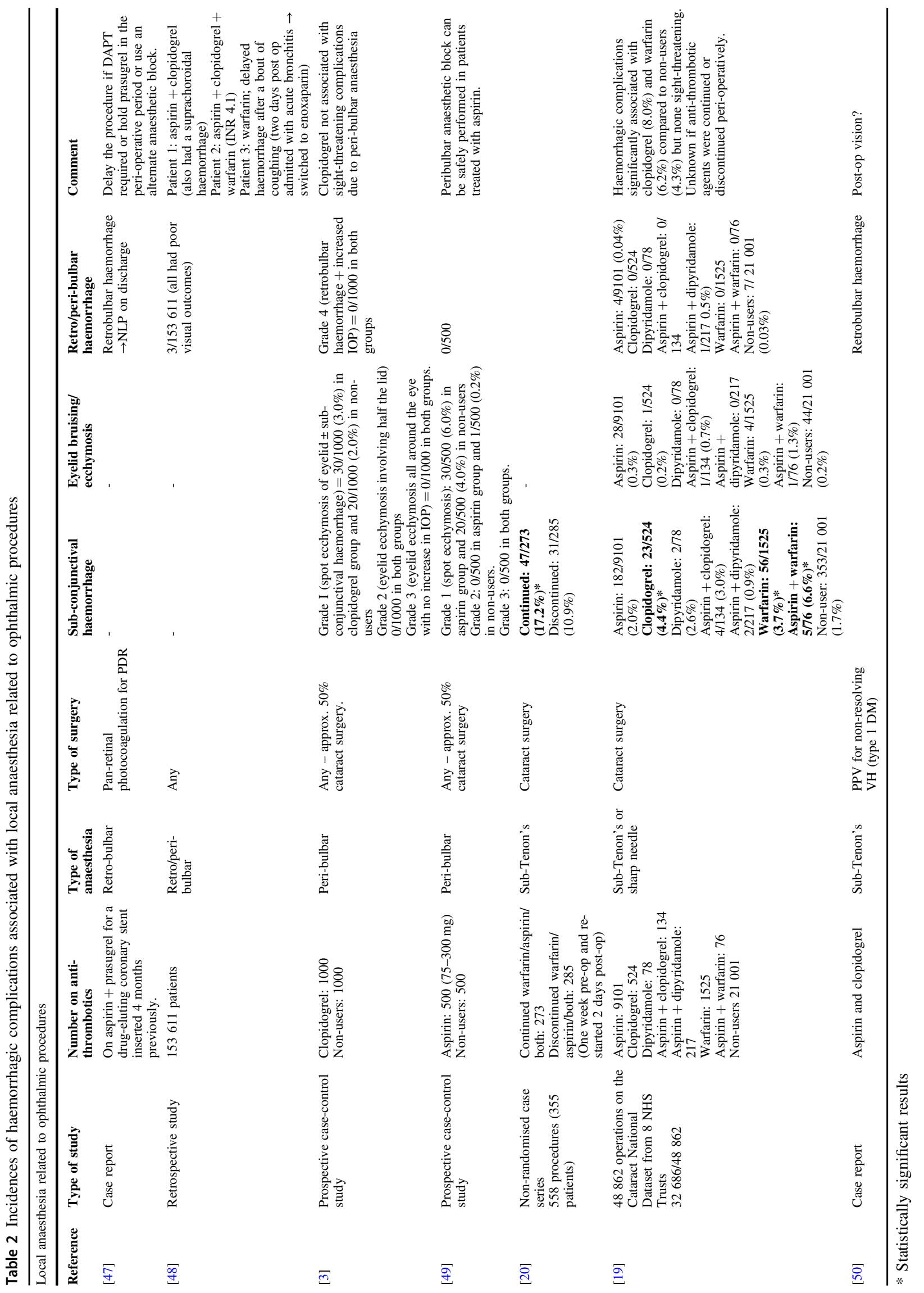




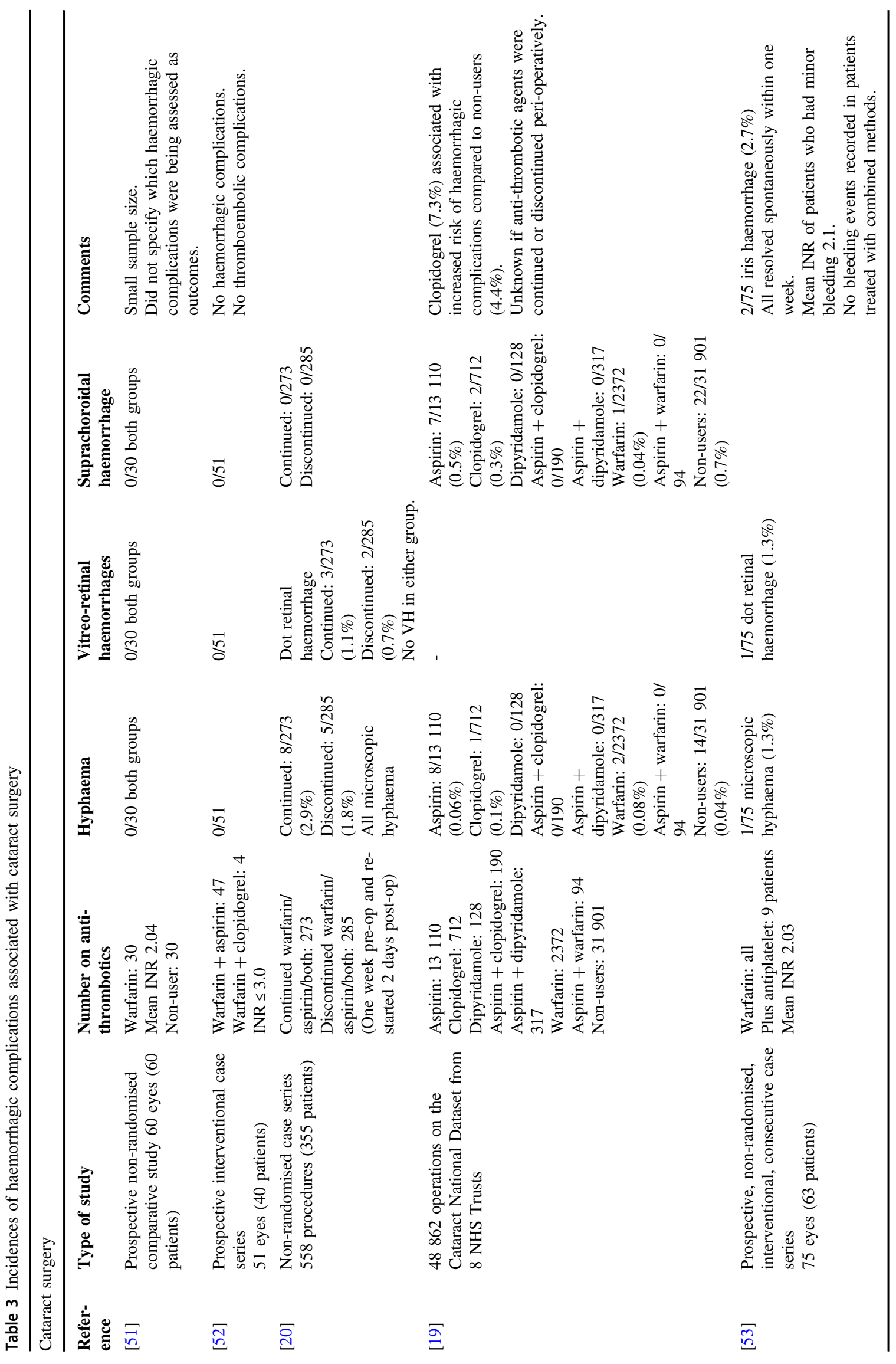


continuing warfarin during cataract surgery [23]. Their guidelines states surgery can be carried out if INR is within therapeutic range and consideration for sub-Tenon's or topical anaesthesia should be given in patients on warfarin to minimise the risk of haemorrhagic complications. Batra et al. recommended that the patients should be informed about the risks and benefits of continuing warfarin therapy during cataract surgery [24]. It has been shown that the risk of stroke increases to 1 in 100 with discontinuing warfarin and the risk of orbital haemorrhage increases by $0.2 \%$ to $1.0 \%$ if warfarin is continued and sharp needle local anaesthesia is performed [24].

To date no study has been designed to evaluate the risk of haemorrhagic complications during cataract surgery related to DOACs. Since DOACs provide more predictable anticoagulation with fixed dosing that is less prone to interaction with other medication compared to warfarin, they theoretically have a risk profile that is equal to or better than warfarin [25]. Therefore, Blum et al. recommended continuing DOACs during the peri-operative period in routine cataract surgery, although they did acknowledge the need for studies in the future to provide an evidence base for recommending guidelines [25]. In our proposed pathway, we suggest that DOACs are omitted 2 days pre-operatively (depending on renal function) and re-started 1 to 2 days post operatively if adequate haemostasis is achieved (Fig. 4 and Table 1).

\section{Glaucoma Surgery}

Alwitry et al. (Table 4) collected data from a questionnaire that was sent to glaucoma specialists in England [13]. They reported that approximately $31 \%$ of the surgeons discontinued aspirin and 33\% discontinued warfarin, of which $14 \%$ routinely started heparin and 38\% started heparin depending on the indication for anticoagulation. Most surgeons $(81.25 \%)$ proceeded with surgery if the INR was three or less, whereas $18.75 \%$ operated at higher INR. Interestingly, a similar study done in Brazil, reported that $82.7 \%$ of glaucoma surgeons stopped aspirin and warfarin [26].

Studies have shown an increased risk of haemorrhagic complications with anti-thrombotic use in glaucoma surgery. One study showed that aspirin use is associated with an increased incidence of hyphaema (50.9\%) compared to anti-thrombotic non-users $(28.0 \%)$, however, this did not affect the surgical outcome at 2 years [27]. In this study, the five patients who were on warfarin, all had significant hyphaema that lead to trabeculectomy failure in four of the five patients. The authors recommended continuing aspirin but discontinuing warfarin peri-operatively during glaucoma surgery. Multivariate analysis has shown that anticoagulant use and high pre- and post-operative intraocular pressures (IOP) to be risk factors for haemorrhagic complications [28]. Kojima et al. reported the incidence of
Fig. 4 Proposed pathway for the peri-operative management of ophthalmic patients on antithrombotic agents

\begin{tabular}{|c|c|c|c|c|c|}
\hline \multicolumn{3}{|c|}{ LOW RISK SURGERY } & \multicolumn{3}{|c|}{ HIGH RISK SURGERY } \\
\hline \multicolumn{3}{|c|}{$\begin{array}{l}\text { - Sub-Tenon/topical cataract surgery } \\
\text { - } \quad \text { Corneal surgery } \\
\text { Oculoplastic: chalazion, eyelid cyst/lesion } \\
\text { removal } \\
\text { - Strabismus }\end{array}$} & \multicolumn{3}{|c|}{$\begin{array}{l}\text { - } \quad \text { Peri/retro-bulbar anaesthesia } \\
\text { - } \quad \text { Glaucoma surgery } \\
\text { - Vitreo-retinal surgery (PPV) } \\
\text { - } \quad \text { itreo-retinal surgery (oncology: endoresection, } \\
\text { biopsy of intraocular tumours, plaques/markers } \\
\text { - Oculoplastics: blepharoplasty, post-septal eyelid } \\
\text { - } \quad \text { surgery } \\
\text { Temporal artery biopsy }\end{array}$} \\
\hline \multirow[t]{2}{*}{ ANTIPLATELETS } & \multicolumn{2}{|c|}{ ANTICOAGULANTS } & \multirow{2}{*}{ ANTIPLATELETS } & \multicolumn{2}{|c|}{ ANTICOAGULANTS } \\
\hline & Warfarin & DOACs & & Warfarin & DOACs \\
\hline Continue. & $\begin{array}{l}\text { Check INR on } \\
\text { day of surgery } \\
\text { and continue if } \\
\text { within } \\
\text { therapeutic } \\
\text { range. }\end{array}$ & $\begin{array}{l}\text { Omit dose } 2 \\
\text { days pre- } \\
\text { operatively } \\
\text { (depends on } \\
\text { renal function) } \\
\text { and re-start 1-2 } \\
\text { days post } \\
\text { operatively if } \\
\text { adequate } \\
\text { haemostasis } \\
\text { achieved. }\end{array}$ & $\begin{array}{l}\text { Aspirin/clopidogrel: } \\
\text { stop } 7 \text { days pre- } \\
\text { operatively, continue } \\
\text { in high risk. } \\
\text { Prasugrel: stop } 7 \text { days } \\
\text { pre-operatively* } \\
\text { Ticagrelor: stop } 5 \\
\text { days pre-operatively* }\end{array}$ & $\begin{array}{l}\text { Inform the local } \\
\text { anti-coagulant } \\
\text { service at time } \\
\text { of listing. } \\
\text { If low risk (e.g. } \\
\text { non-valvular } \\
\text { atrial } \\
\text { fibrillation): } \\
\text { stop } 2 \text { days pre- } \\
\text { operatively, } \\
\text { check INR on } \\
\text { day of surgery, } \\
\text { and continue if } \\
<2 \text {. Re-start on } \\
\text { evening of } \\
\text { surgery. } \\
\text { If high risk: } \\
\text { discuss with } \\
\text { physician. }\end{array}$ & $\begin{array}{l}\text { Omit dose } 2 \\
\text { days pre- } \\
\text { operatively } \\
\text { (depends on } \\
\text { renal function) } \\
\text { and re-start 1-2 } \\
\text { days post } \\
\text { operatively if } \\
\text { adequate } \\
\text { haemostasis } \\
\text { achieved. }\end{array}$ \\
\hline
\end{tabular}




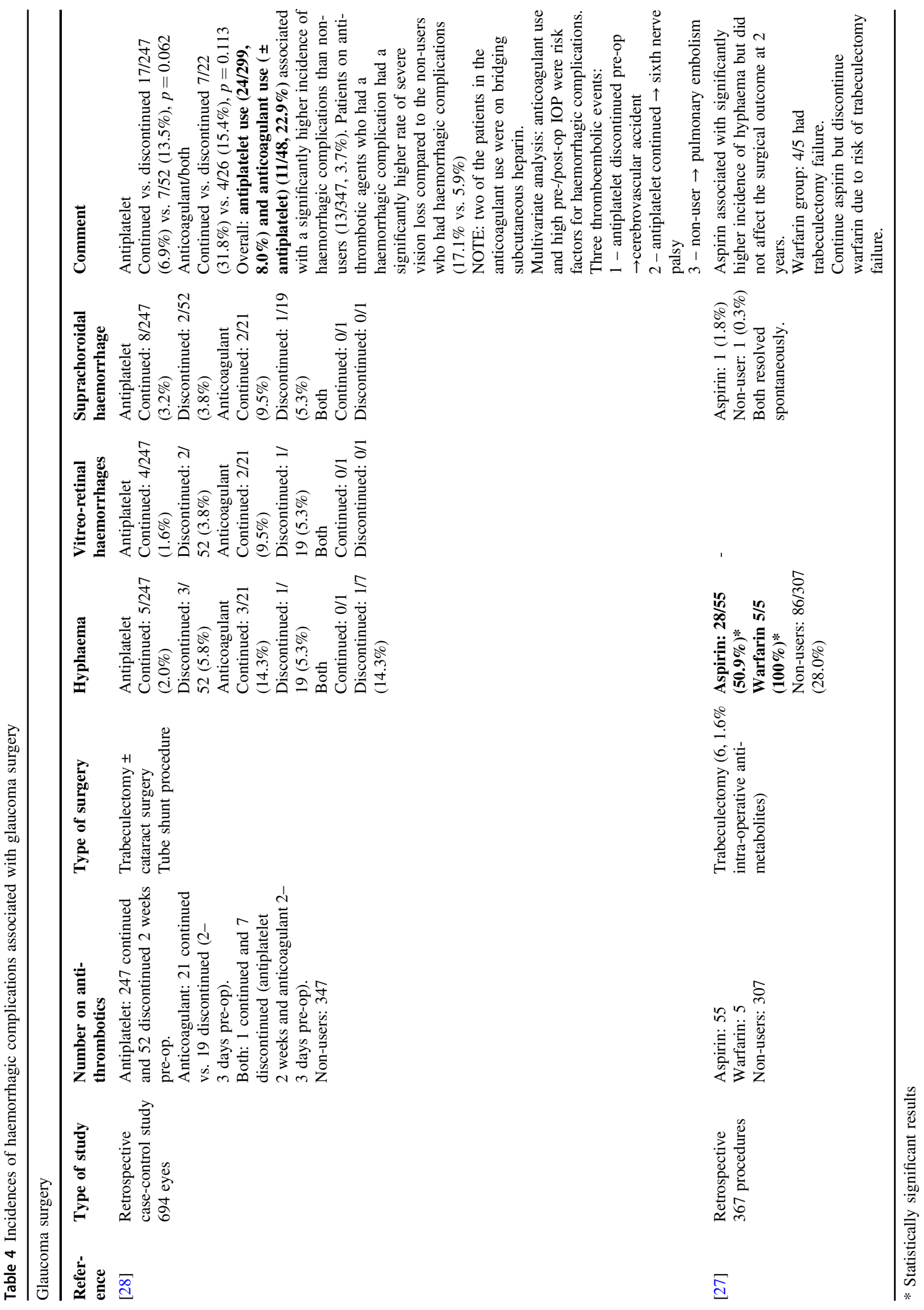


hyphaema to be $24.8 \%$ in a Japanese population of patients undergoing trabeculectomy with mitomycin $C$ [29]. They showed that neovascular glaucoma and antiplatelet and anticoagulant use are associated with an increased risk of hyphaema (OR: 2.4, $p=0.0017$ and OR: $2.1, p=0.0274$, respectively). Of the patients with neovascular glaucoma, the risk is further increased with antiplatelet and anticoagulant use (OR 3.3, $p=0.0450)$. Pre-operative use of intravitreal anti-vascular endothelial growth factor (VEGF) injections was associated with a reduced risk in these patients (OR 0.36, $p=0.0275$ ) [29].

Golan et al. undertook a prospective controlled study in patients suspected of bilateral primary angle-closure glaucoma who were on antiplatelet or anticoagulant agents undergoing laser peripheral iridotomy [30]. They included 104 patients (204 eyes) of which, 49\% were on aspirin, $32.7 \%$ were on warfarin and $18.3 \%$ were on clopidogrel. One eye had the procedure while on anti-thrombotic agents, whereas these agents were discontinued for 2 weeks prior to having the procedure in the second eye. The incidences of hyphaema in both eyes were $34.6 \%$ (36/104), which was not statistically significant irrespective of the antithrombotic agent used. The incidence of hyphaema when anti-thrombotic agents were continued were $31.4 \%$ for patients on aspirin, $41.2 \%$ for warfarin and $31.6 \%$ for clopidogrel. All the hyphaemas were either grade 1 (minor bleeding stopped by light pressure with Abraham contact lens) or 2 (bleeding not controlled with contact lens and no macroscopic hyphaema) [30].

Therefore, the recommendations in the literature are to discontinue aspirin and clopidogrel when used as monotherapy for primary prevention, however, continue if used for secondary prevention of cardiovascular diseases. The $\mathrm{P}^{2} \mathrm{Y}_{12}$ receptor inhibitors should be discontinued if used as DAPT. However, risks and benefits of continuing antiplatelet agents should be considered in the presence of neovascular glaucoma and high IOPs. It is also important to consider and recognise that, intraoperative and postoperative haemorrhagic complications in glaucoma, especially if sustained or prolonged, can cause severe visual loss due to high pressure in already compromised optic nerves. Anticoagulants should be discontinued with consideration for bridging therapy depending on patient's risk factors.

\section{Vitreo-Retinal Surgery}

A recent survey that included 167 (Table 5) members of the British and Eire Association of Vitreoretinal Surgeons showed that $93 \%$ and $82 \%$ of the respondents continued aspirin and clopidogrel peri-operatively, respectively [7]. Moreover, $79 \%$ of the respondents reported to continuing warfarin and 58\% continued DOACs peri-operatively. More than $90 \%$ of the surgeons would continue with surgery if the INR is between 1.0 and 3.0, $43 \%$ if INR between 3.0 and 3.5 and only $7 \%$ would continue with surgery if INR is more than 3.5. In this survey, only $9 \%$ of the surgeons reported to stopping all anticoagulant agents during diabetic vitrectomy and retinectomy [7].

The incidence of post-operative vitreous haemorrhage following vitrectomy for complications of proliferative diabetic retinopathy (PDR) is reported to be between 20 and $30 \%$ [7]. Patel et al. carried out cumulative data analysis of studies, who reported incidence rates of haemorrhagic complications to be $17.5 \%$ (36 of 206 eyes) with aspirin, $7.4 \%$ (15 of 204 eyes) with clopidogrel, $16.7 \%$ (7 of 42 eyes) with dual therapy with aspirin and clopidogrel, $13 \%$ ( 3 of 23 eyes) with prasugrel, $8.3 \%$ (22 of 266 eyes) with warfarin and $7.7 \%$ ( 1 of 13 eyes) with DOACs [7].

Chandra et al. undertook a prospective study on 5459 patients that underwent pars plana vitrectomy over a ten year period and looked at the incidence of suprachoroidal haemorrhages [31]. Suprachoroidal haemorrhages were observed in 56 patients (1.03\%) during the study period. Multivariable logistic regression showed use of aspirin and warfarin (OR 2.29, $p=0.007$ ) to be risk factors for developing suprachoroidal haemorrhages [31]. Another study by Brillat et al. reported that aspirin continued or discontinued for 5 days or less peri-operatively was not associated with an increased risk of haemorrhagic complications during retinal detachment surgery [32]. In contrast, a retrospective study by Ryan et al. did not show anti-thrombotic agents to be a risk factor for intra and post-operative haemorrhagic complications [33]. Similarly, another study by Brown et al. concluded that there was no increased risk of post-operative dense vitreous haemorrhages in patients undergoing diabetic vitrectomy between patients on aspirin, clopidogrel or warfarin compared to those who discontinued these medication peri-operatively or non-users [34]. However, studies have shown PDR (OR 4.1, $p=0.003$ ) and diabetes (OR $18.5, p<0.001)$ to be risk factors for intra and postoperative haemorrhagic complications, respectively [33]. Use of anti-VEGF injections to reduce post-operative recurrent vitreous haemorrhages is becoming popular in patients with PDR [33, 35]. Fabinyi et al. reported that diabetic patients undergoing PPV while on anti-thrombotic agents (aspirin/clopidogrel/warfarin) peri-operatively are more likely to have persistent vitreous haemorrhage (OR $4.8, p=0.004)$ and subsequent surgery (OR 6.6, $p=0.024)$ [35]. Oh et al. reported glaucoma also be a risk factor associated with haemorrhagic complications following vitreoretinal surgery [1].

Due to controversial results from studies, the recommendations for peri-operative management is similar to that for glaucoma surgery. Anti-thrombotic agents are to be discontinued where possible and to be cautious of these agents in the presence of neovascular retinal diseases. 


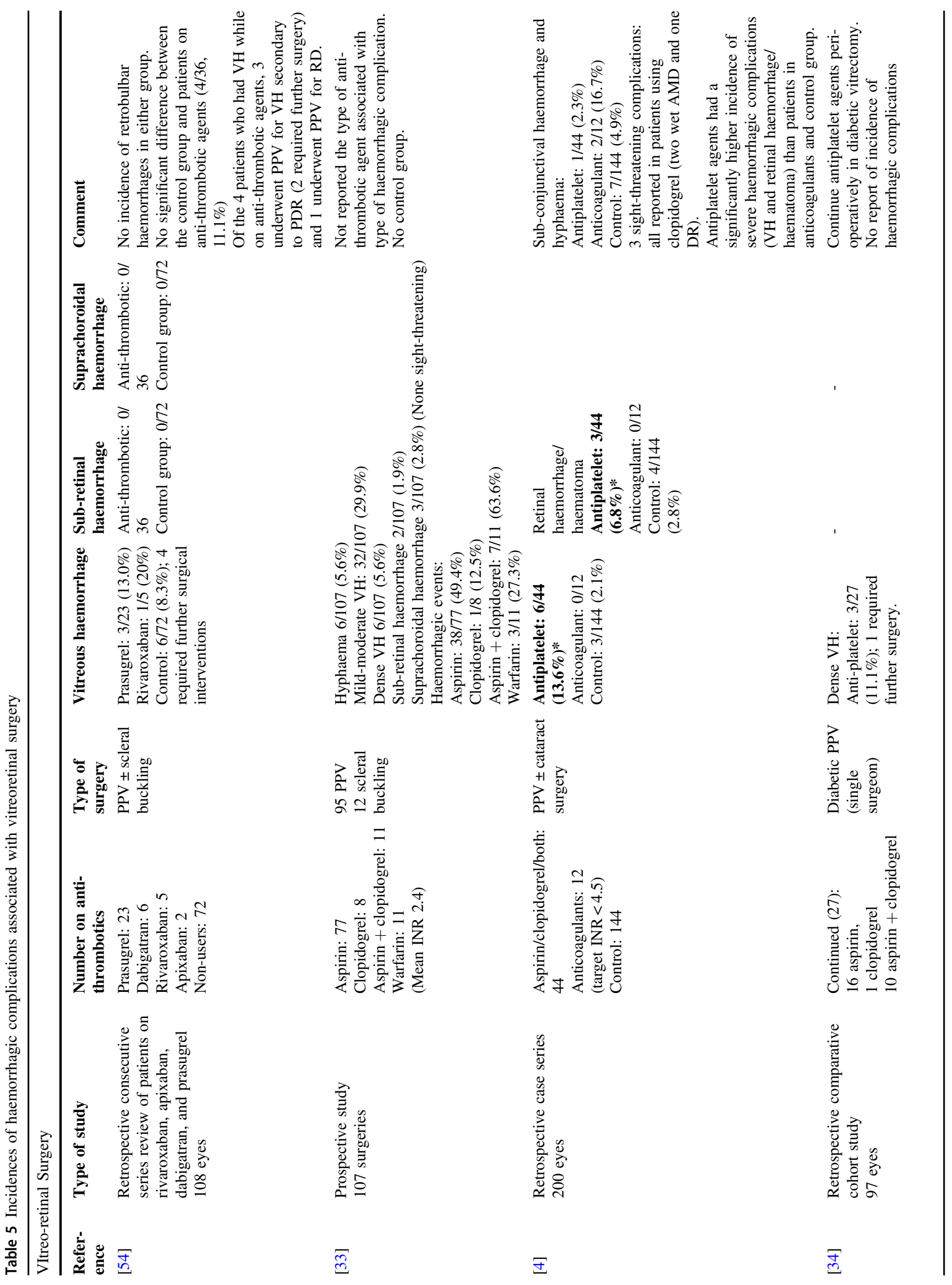



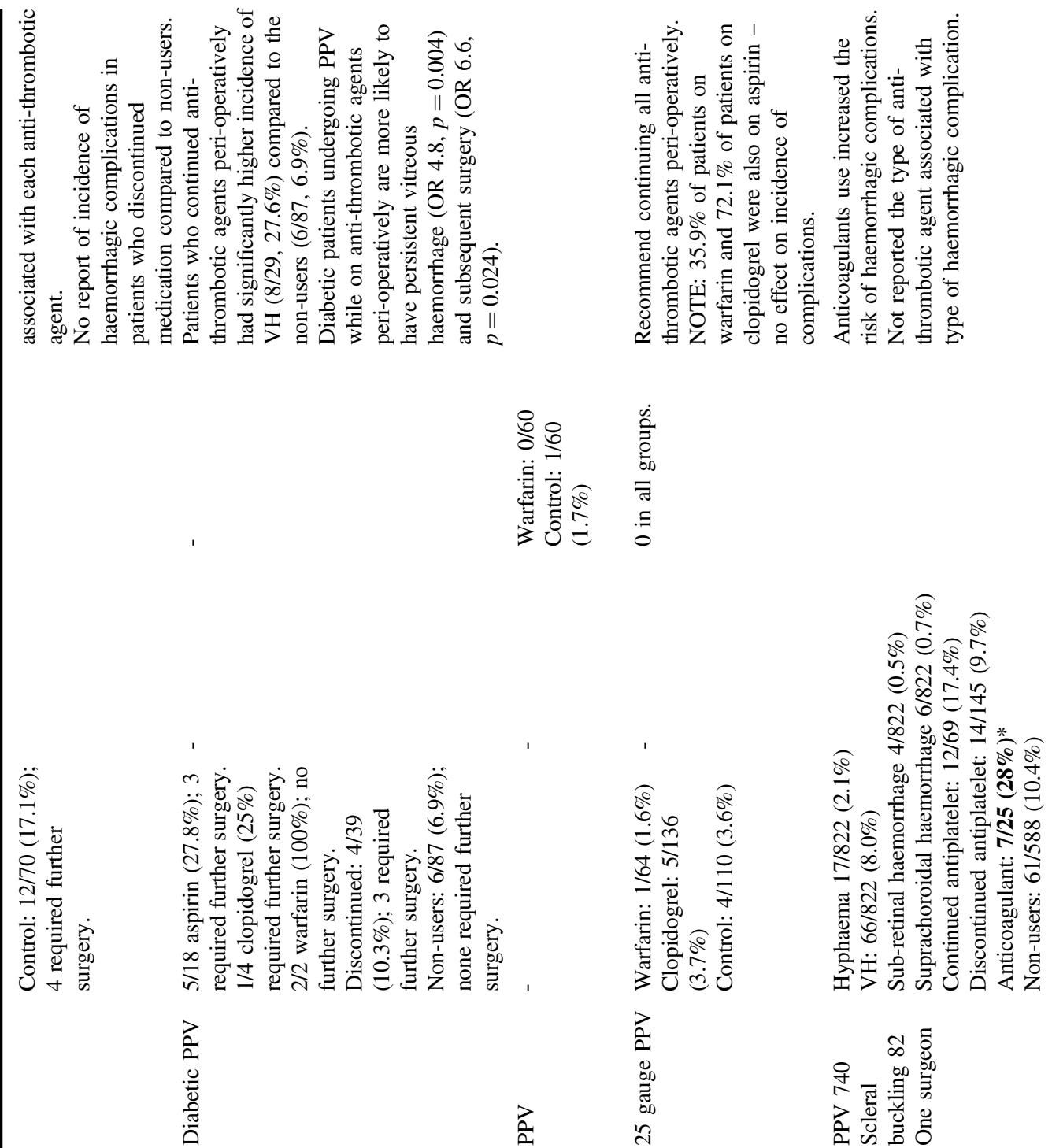

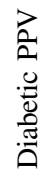

$\frac{2}{2}$

品

용

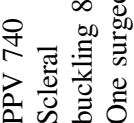

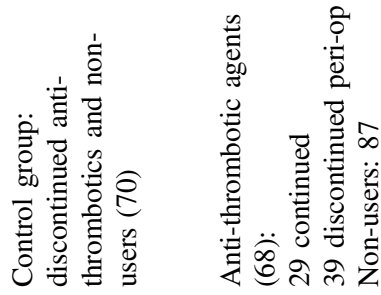
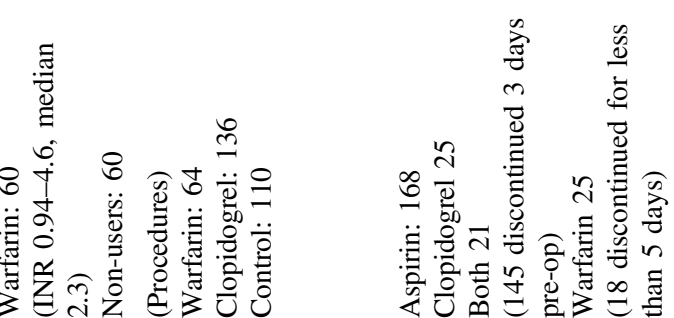

3
0
0
0
0
0
0
0
0
0
0
0
0
0
0
0
0
0
0

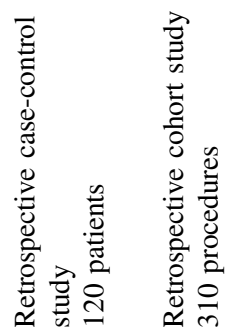

$\sqrt[n]{2}$

$\stackrel{n}{n} \quad \stackrel{0}{2}$

己. 


\section{Oculoplastic And Lacrimal Surgery}

In general, eyelid procedures anterior to the orbital septum (Table 6) (chalazion and eyelid lesion removal) are associated with low risk of sight-threatening haemorrhagic complications, whereas eyelid procedures posterior to the septum (ptosis surgery and lower lid blepharoplasty) and deep orbital surgery are associated with potentially sight-threatening haemorrhagic complications $[5,6]$. Lacrimal surgery, such as dacrocystorhinostomy, is also associated with a moderate risk of epistaxis are also classed as a high-risk procedure [5, 6]. There are sparse studies done to investigate the risk of haemorrhagic complications in patients on anti-thrombotic agents undergoing oculoplastic and lacrimal surgery. Expert groups on oculoplastic surgery recommend stopping antithrombotic agents during blepharoplasty, lacrimal surgery and deep orbital surgery as these are considered high risk for sight-threatening haemorrhagic complications [5].

There were only two retrospective chart review studies found during our literature review on patients undergoing oculoplastic and lacrimal surgery. One study showed a significantly higher incidence of intra-operative haemorrhage during high-risk oculoplastic procedures in patients who discontinued anti-thrombotic agents preoperatively compared to non-users, however, there was no significant difference in the incidence of haemorrhagic complications in patients who continued their antithrombotic medication peri-operatively and non-users [36]. The second study included patients who had patients that discontinued their anti-thrombotic medication pre-dacrocystorhinostomy and reported no increased risk of delayed epistaxis in these patients compared to non-users [37].

To date there are no studies investigating the safety of continuing DOACs peri-operatively in patients undergoing oculoplastic and lacrimal surgery. However, due to the better safety profile of DOACs compared to warfarin, it may be advisable to follow the same recommendations made for warfarin with DOACs [6]. Liu et al. presented two case reports of patients on rivaroxaban who had haemorrhagic complications after uncomplicated eyelid surgery [38]. Patient 1 had bilateral upper blepharoplasty who stopped rivaroxaban $24 \mathrm{~h}$ pre-operatively, however, despite medical advice re-started medication the evening of the surgery. He presented with left eye orbital compartment syndrome. Following decompression, the post op vision was 20/20. The second patient had bilateral ectropion repair who was on rivaroxaban that was stopped $24 \mathrm{~h}$ pre-operatively and re-started medication $8 \mathrm{~h}$ postoperatively. Within $2 \mathrm{~h}$ of re-starting rivaroxaban patient presented with left lower eyelid bleeding that stopped with electrocautery and Surgicel with no sequalae [38].

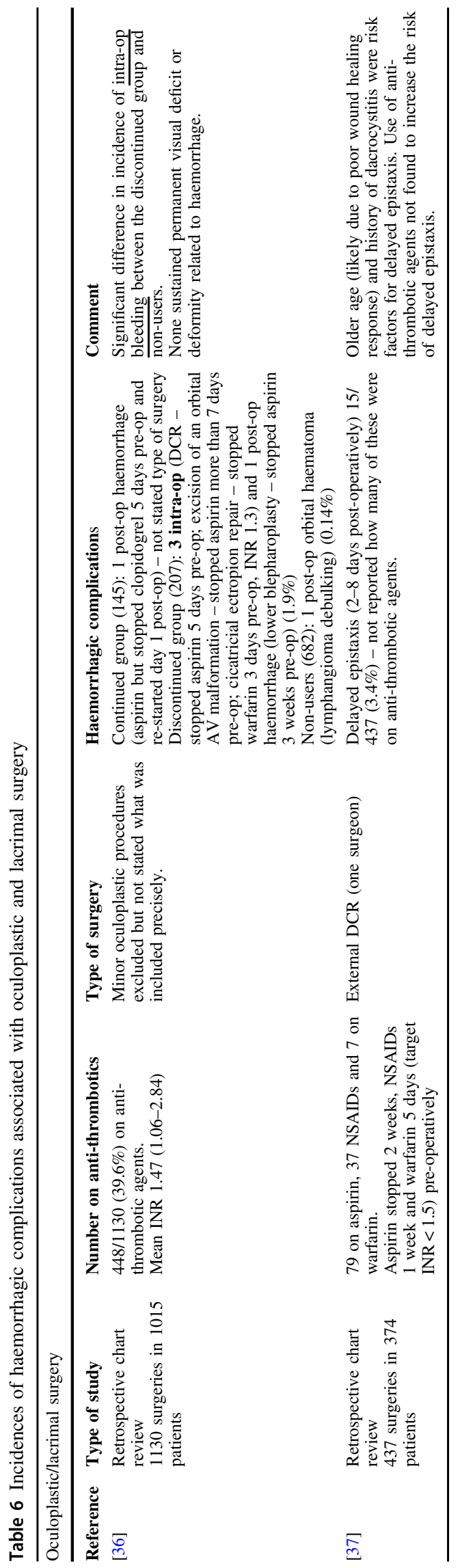


Due to the rapid onset of action of DOACs, it is recommended not to re-start these medications too soon after high-risk procedures [6].

In patients undergoing high-risk procedures who are also at high risk of thromboembolic events and are unable to discontinue their regular medication, it is recommended to discuss with patients regarding alternate or less invasive treatments or to alter the surgical technique if possible to reduce haemorrhage [6]. If it is essential to discontinue antithrombotic agents, it is advised that a discussion with the cardiology team is made [5].

\section{Strabismus Surgery}

There was only one study that reported the incidence of haemorrhagic (Table 7) complications associated with antithrombotic agents in patients undergoing strabismus surgery. Kemp et al. retrospectively identified three patients who continued warfarin out of 155 patients that underwent strabismus surgery [39]. They reported that all three patients had INR within the therapeutic range of 2.0 to 3.0 and none had haemorrhagic complications. However, they did not report on patients who were on antiplatelet agents and their associated risk of haemorrhagic complications. Recommendations in the literature for the peri-operative management of anti-thrombotic agents are similar to glaucoma and vitreoretinal surgery.

\section{Corneal Surgery}

Haemorrhage-related complications are rare but well recognised in corneal surgery due to the devastating consequence of vision loss. The incidence of suprachoroidal haemorrhages in penetrating keratoplasty (PKP) have been reported to be $0.73 \%$ [40]. In 'open sky' scenarios, eyes are at an increased risk of an expulsive choroidal haemorrhage due to sudden globe decompression. Park et al. reported the incidence of vitreous haemorrhage in PKPs as 0.75\% [41]. Delayed suprachoroidal haemorrhages have been reported after Descemet stripping automated endothelial keratoplasty (DSAEK) [42, 43].

Whilst there has been an association of spontaneous suprachoroidal haemorrhage with the use of systemic anticoagulants or thrombolytic agents in the absence of surgery or trauma [44, 45], we did not identify any studies published that evaluated the use of anti-thrombotic agents in corneal surgery. Crews et al. found that the pre-operative use of anticoagulant and antiplatelet medications did not increase the risk of hyphaema from the intraoperative peripheral iridotomy in Descemet membrane endothelial keratoplasty (DMEK) [46].

Expert opinion recommends antiplatelet monotherapy to be continued and second agent to be discontinued if 
dual therapy is used during keratoplasty and surgery for pterygium [21]. They recommend warfarin to be continued if INR is within therapeutic range and DOACs to be discontinued if after the high thrombotic risk period due to the lack of evidence on DOACs [21].

\section{Our Recommendations}

Our recommendations made following the literature review and advice from our local ophthalmology consultants are shown in Fig. 4.

\section{Conclusions}

Most studies in the literature are retrospective and are not of the highest quality of evidence, such as RCTs. Moreover, the incidences of haemorrhagic complications are rare limiting the statistical power of studies.

In any case it is important to consider the indication for anti-thrombotic agents and the risk of thromboembolic events, as well as risk of haemorrhagic complications depending on patient and surgical factors. Bridging anticoagulation should be considered when oral anticoagulant agents are discontinued. The most appropriate surgical procedure should be offered to the patient depending on the risk of haemorrhage peri-operatively when anti-thrombotic agents are continued. When urgent surgery is required or when a patient's case is complex, it is important to take a multidisciplinary approach to the peri-operative management of anti-thrombotic agents.

\section{Compliance with ethical standards}

Conflict of interest The authors declare that they have no conflict of interest.

Publisher's note: Springer Nature remains neutral with regard to jurisdictional claims in published maps and institutional affiliations.

\section{References}

1. Oh J, Smiddy WE, Kim SS. Antiplatelet and anticoagulation therapy in vitreoretinal surgery. Am J Ophthalmol. 2011;151:934 939.e3.

2. Keeling D, Tait RC, Watson H. British Committee of Standards for Haematology. Peri-operative management of anticoagulation and antiplatelet therapy. Br J Haematol. 2016;175:602-13.

3. Calenda E, Lamothe L, Genevois O, Cardon A, Muraine M. Peribulbar block in patients scheduled for eye procedures and treated with clopidogrel. J Anesth. 2012;26:779-82.

4. Passemard M, Koehrer P, Juniot A, Bron AM, Creuzot-Garcher C. Maintenance of anticoagulant and antiplatelet agents for patients undergoing peribulbar anesthesia and vitreoretinal surgery. Retina. 2012;32:1868-73.
5. Esparaz ES, Sobel RK. Perioperative management of anticoagulants and antiplatelet agents in oculoplastic surgery. Curr Opin Ophthalmol. 2015;26:422-8.

6. Ing E, Douketis J. New oral anticoagulants and oculoplastic surgery. Can J Ophthalmol. 2014;49:123-7.

7. Patel R, Charles S, Jalil A. Antiplatelets and anticoagulants in vitreoretinal surgery, with a special emphasis on novel anticoagulants: a national survey and review. Graefes Arch Clin Exp Ophthalmol. 2017;255:1275-85.

8. Kong KL, Khan J. Ophthalmic patients on antithrombotic drugs: a review and guide to perioperative management. $\mathrm{Br} \mathrm{J}$ Ophthalmol. 2015;99:1025-30.

9. van Veen JJ, Makris M. Management of peri-operative antithrombotic therapy. Anaesthesia. 2015;70(Suppl 1):58-67-e21-3.

10. Lip GY, Durrani OM, Roldan V, Lip PL, Marin F, Reuser TQ. Peri-operative management of ophthalmic patients taking antithrombotic therapy. Int J Clin Pract. 2011;65:361-71.

11. Healey JS, Eikelboom J, Douketis J, Wallentin L, Oldgren J, Yang $\mathrm{S}$, et al. RE-LY Investigators. Periprocedural bleeding and thromboembolic events with dabigatran compared with warfarin: results from the Randomized Evaluation of Long-Term Anticoagulation Therapy (RE-LY) randomized trial. Circulation. 2012;126:343-8.

12. Sun MT, Wood MK, Chan W, Selva D, Sanders P, Casson RJ, et al. Risk of intraocular bleeding with novel oral anticoagulants compared with warfarin: a systematic review and meta-analysis. JAMA Ophthalmol. 2017;135:864-70.

13. Alwitry A, King AJ, Vernon SA. Anticoagulation therapy in glaucoma surgery. Graefes Arch Clin Exp Ophthalmol. 2008;246:891-6.

14. Kiire CA, Mukherjee R, Ruparelia N, Keeling D, Prendergast B, Norris JH. Managing antiplatelet and anticoagulant drugs in patients undergoing elective ophthalmic surgery. Br J Ophthalmol. 2014;98:1320-4.

15. Mather SJ, Kong KL, Vohra SB. Loco-regional anaesthesia for ocular surgery: anticoagulant and antiplatelet drugs. Curr Anaesth \& Crit Care. 2010;21:158-63.

16. The Royal College of Ophthalmologists. National Ophthalmology Database Audit. London:RCOphth. 2018. https://www.nodaudit. org.uk/u/docs/20/avusuryktz/NOD\%20Audit\%20Annual\% 20Report\%202018.pdf. Accessed 23 Dec 2018.

17. National Institute for Health and Care Excellence. Cataracts in adults: management. Full guideline. London:NICE; 2017. https://www.nice.org.uk/guidance/ng77/resources/cataracts-in-a dults-management-pdf-1837639266757. Accessed 23 Dec 2018.

18. Lee RM, Thompson JR, Eke T. Severe adverse events associated with local anaesthesia in cataract surgery: 1 year national survey of practice and complications in the UK. $\mathrm{Br} \mathrm{J}$ Ophthalmol. 2016;100:772-6.

19. Benzimra JD, Johnston RL, Jaycock P, Galloway PH, Lambert G, Chung AK, et al. EPR User Group. The Cataract National Dataset electronic multicentre audit of 55,567 operations: antiplatelet and anticoagulant medications. Eye (Lond). 2009;23:10-6.

20. Kobayashi $\mathrm{H}$. Evaluation of the need to discontinue antiplatelet and anticoagulant medications before cataract surgery. J Cataract Refract Surg. 2010;36:1115-9.

21. Bonhomme F, Hafezi F, Boehlen F, Habre W. Management of antithrombotic therapies in patients scheduled for eye surgery. Eur J Anaesthesiol. 2013;30:449-54.

22. Jamula E, Anderson J, Douketis JD. Safety of continuing warfarin therapy during cataract surgery: a systematic review and metaanalysis. Thromb Res. 2009;124:292-9.

23. The Royal College of Ophthalmologists. Cataract surgery guidelines. London:RCOphth. 2010. https://www.rcophth.ac.uk/wpcontent/uploads/2014/12/2010-SCI-069-Cataract-Surgery- 
Guidelines-2010-SEPTEMBER-2010-1.pdf. Accessed 20 Jan 2018.

24. Batra R, Maino A, Ch'ng SW, Marsh IB. Perioperative management of anticoagulated patients having cataract surgery: National audit of current practice of members of the Royal College of Ophthalmologists. J Cataract Refract Surg. 2009;35:1815-20.

25. Blum RA, Lindfield D. Direct oral anticoagulant drugs (DOAC). J Cataract Refract Surg. 2016;42:171-2.

26. Balbino M, Boin P, Prata TS. Perioperative management of anticoagulant users scheduled for glaucoma surgery: a survey among the Brazilian Glaucoma Society members. Arq Bras Oftalmol. 2013;76:363-5.

27. Cobb CJ, Chakrabarti S, Chadha V, Sanders R. The effect of aspirin and warfarin therapy in trabeculectomy. Eye (Lond). 2007;21:598-603.

28. Law SK, Song BJ, Yu F, Kurbanyan K, Yang TA, Caprioli J. Hemorrhagic complications from glaucoma surgery in patients on anticoagulation therapy or antiplatelet therapy. Am J Ophthalmol. 2008;145:736-46.

29. Kojima S, Inatani M, Shobayashi K, Haga A, Inoue T, Tanihara H. Risk factors for hyphema after trabeculectomy with mitomycin C. J Glaucoma. 2014;23:307-11.

30. Golan S, Levkovitch-Verbin H, Shemesh G, Kurtz S. Anterior chamber bleeding after laser peripheral iridotomy. JAMA Ophthalmol. 2013;131:626-9.

31. Chandra A, Xing W, Kadhim MR, Williamson TH. Suprachoroidal hemorrhage in pars plana vitrectomy: risk factors and outcomes over 10 years. Ophthalmology. 2014;121:311-7.

32. Brillat E, Rouberol F, Palombi K, Quesada JL, Bernheim D, Albaladejo P, et al. A case-control study to assess aspirin as a risk factor of bleeding in rhegmatogenous retinal detachment surgery. Graefes Arch Clin Exp Ophthalmol. 2015;253:1899-905.

33. Ryan A, Saad T, Kirwan C, Keegan DJ, Acheson RW. Maintenance of perioperative antiplatelet and anticoagulant therapy for vitreoretinal surgery. Clin Exp Ophthalmol. 2013;41:387-95.

34. Brown JS, Mahmoud TH. Anticoagulation and clinically significant postoperative vitreous hemorrhage in diabetic vitrectomy. Retina. 2011;31:1983-7.

35. Fabinyi DC, O'Neill EC, Connell PP, Clark JB. Vitreous cavity haemorrhage post-vitrectomy for diabetic eye disease: the effect of perioperative anticoagulation and antiplatelet agents. Clin Exp Ophthalmol. 2011;39:878-84.

36. Kent TL, Custer PL. Bleeding complications in both anticoagulated and nonanticoagulated surgical patients. Ophthal Plast Reconstr Surg. 2013;29:113-7.

37. Ben Simon GJ, Cheung N, McNab AA. Delayed epistaxis in external dacryocystorhinostomy: rate and risk factors. Arch Otolaryngol Head Neck Surg. 2010;136:183-6.

38. Liu CY, Samimi DB, Tao JP. Hemorrhagic complications of rivaroxaban after eyelid surgery. Ophthal Plast Reconstr Surg. 2016;32:74

39. Kemp PS, Larson SA, Drack AV. Strabismus surgery in patients receiving warfarin anticoagulation. J AAPOS. 2014;18:84-6.
40. Bandivadekar P, Gupta S, Sharma N. Intraoperative suprachoroidal hemorrhage after penetrating keratoplasty: case series and review of literature. Eye Contact Lens. 2016;42:206-10.

41. Park Y, Kim MH, Won JY, Kim HS, Park YH. Vitreoretinal complications after penetrating keratoplasty. Retina. 2016;36:2110-5.

42. Koenig SB. Delayed massive suprachoroidal hemorrhage after descemet stripping automated endothelial keratoplasty. Cornea. 2011;30:818-9.

43. Qian CX, Harissi-Dagher M. Delayed suprachoroidal haemorrhage following Boston Keratoprosthesis in two aniridic patients. Br J Ophthalmol. 2011;95:436-7.

44. Wong JS. Spontaneous suprachoroidal haemorrhage in a patient receiving low-molecular-weight heparin (fraxiparine) therapy. Aust N Z J Ophthalmol. 1999 Dec;27:433-4.

45. Yang SS, Fu AD, McDonald HR, Johnson RN, Ai E, Jumper JM. Massive spontaneous choroidal hemorrhage. Retina. 2003;23:139-44.

46. Crews JW, Price MO, Lautert J, Feng MT, Price FW Jr. Intraoperative hyphema in Descemet membrane endothelial keratoplasty alone or combined with phacoemulsification. J Cataract Refract Surg. 2018;44:198-201.

47. Matharu KS, Smith SV, Lee AG. Retrobulbar hemorrhage and prasugrel. Can J Ophthalmol. 2016;51:e189-e190.

48. Huebert I, Heinicke N, Kook D, Boost KA, Mille CV, Mayer WJ, et al. Dual platelet inhibition in cases of severe retrobulbar hemorrhage following retrobulbar and peribulbar anesthesia. J Cataract Refract Surg. 2015;41:2092-101.

49. Calenda E, Cardon-Guiton A, Genevois O, Gueudry J, Muraine M. Peribulbar block in 500 patients scheduled for eye procedures and treated with acetyl salicylic acid. Acta Anaesthesiol Taiwan. 2011;49:141-3.

50. Subbiah S, McGimpsey S, Best RM. Retrobulbar hemorrhage after sub-Tenon's anesthesia. J Cataract Refract Surg. 2007:33:1651-2.

51. Kara-Junior N, Santhiago MR, Almeida HG, Raiza AC. Safety of warfarin therapy during cataract surgery under topical anesthesia. Arq Bras Oftalmol. 2015;78:173-4.

52. Barequet IS, Sachs D, Shenkman B, Priel A, Wasserzug Y, Budnik I, et al. Risk assessment of simple phacoemulsification in patients on combined anticoagulant and antiplatelet therapy. J Cataract Refract Surg. 2011;37:1434-8.

53. Barequet IS, Sachs D, Priel A, Wasserzug Y, Martinowitz U, Moisseiev $\mathrm{J}$, et al. Phacoemulsification of cataract in patients receiving Coumadin therapy: ocular and hematologic risk assessment. Am J Ophthalmol. 2007;144:719-23.

54. Grand MG, Walia HS. Hemorrhagic risk of vitreoretinal surgery in patients maintained on novel oral anticoagulant therapy. Retina. 2016;36:299-304.

55. Chandra A, Jazayeri F, Williamson TH. Warfarin in vitreoretinal surgery: a case controlled series. Br J Ophthalmol. 2011;95:976-8.

56. Mason JO 3rd, Gupta SR, Compton CJ, Frederick PA, Neimkin MG, Hill ML, et al. Comparison of hemorrhagic complications of warfarin and clopidogrel bisulfate in 25-gauge vitrectomy versus a control group. Ophthalmology. 2011;118:543-7. 